\title{
Application of Operational Analysis for Evaluation of the Impact of Different Factors on Performance Efficiency of the Enterprises Forming the Regional Industrial Cluster
}

\author{
Alexander Nikolayevich Melnik ${ }^{1}$ \\ Alena Nikolayevna Dyrdonova1,2 \\ ${ }^{1}$ Kazan Federal University, 420008, Russia, Kazan \\ ${ }^{2}$ Nizhnekamsk Chemical Technology Institute (branch) of Kazan National Research Technological University \\ 423570, Russia Nizhnekamsk; E-mail: danauka@lenta.ru
}

Doi:10.5901/mjss.2015.v6n6p141

\section{Abstract}

Budgets of different levels are mainly formed by performance of the enterprises making part of various industrial clusters, including, first of all, the regional industrial clusters having a decisive impact on social and cultural development of the particular region. So it is no wonder that performance efficiency of such enterprises is scrutinized by the regional management bodies. Improvement of performance efficiency of the enterprises involved in the regional clusters is dependent on quite a few external and internal factors. This paper includes a review of the methodological approach designed for evaluation of the effect produced by such factors on performance of the enterprises making part of the industrial cluster of the particular region, which could be used for mapping out a development strategy for such enterprises, for planning their current and future business activities, as well as for identification of possible effects of decision-making process taking place at a management level. Practical aspects of the scope of application of the proposed methodological approach have been reviewed, which are accommodated to the business environment in which the enterprises making part of one of the largest regional petrochemical clusters in Russia operate.

Keywords: region, industrial cluster, petrochemical cluster, efficiency, operational analysis, profit, factors, modeling.

\section{Introduction}

A paramount prerequisite for moving the Russian economy towards sustainable development is a sizable improvement of performance efficiency of the regional economic systems. It is apparent that the issue should be addressed taking into consideration the peculiarities of social and economic development of different regions whilst required to be supported by a corresponding cluster-based infrastructure. It is worth noting that the cluster-based infrastructure is instrumental in advancement of the regional economic systems. The cluster-based infrastructure is predetermined, in the first place, by creation of all conditions necessary for operation of the production industries, as well as for realization of the functions being of marginal significance from the point of view of social and economic development. In the second place, the cluster-based infrastructure may be regarded as a driving force for the regional development, which could serve to facilitate achievement of expectations with respect to the expanded regional reproduction. Therefore, all efforts aimed at improvement of the performance efficiency should be closely linked to the social and economic development strategies and accounted for when mapping out strategic programs designed for advancement of respective regional industrial clusters and geographical clusters.

Since 2008, the industrial complex operating in the Republic of Tatarstan that represents one of the most industrially well-developed regions of the Russian Federation has been managed based on the cluster-type development model (Melnik and Dyrdonova, 2014) which was built using the principle of taking all advantages of cluster-type development, inclusive of comprehensive enhancement of interfirm co-operation, effective subcontracting, application of state-of-art management technologies etc. Higher competitive ability of the primary enterprises forming the core of the cluster must provide background for advancement of other members within the cluster, including all small-size businesses, service and specialized service enterprises, R\&D and educational centers etc.

The petrochemical sector is a priority area of development of the economy of the Republic of Tatarstan. Consequently, special emphasis is laid on promotion of the petrochemical cluster. The primary enterprise catering for the petrochemical sector not only of the Republic of Tatarstan but the Russian Federation as a whole is the Public JointStock Company Nizhnekamskneftekhim (Melnik and Dyrdonova, 2015). That is why the issues related to improvement of 
production, commercial and financial performance efficiency of Nizhnekamskneftekhim appear to be extremely vital in the current context.

\subsection{Purpose of the study}

Efficiency of performance of the enterprises operating in the regional cluster is influenced by a number of factors. This circumstance, in its turn, underlies the need for new approaches to how to manage the performance efficiency of the enterprises being members of the cluster subject to the degree of impact of the external and internal factors on the functioning of the clusters. Therefore, the main purpose of the conducted study was development of a methodological approach to assessment of the factors influencing the performance of the enterprises, which could be used for both making on-the-spot decisions on management level and solving any strategic development-related issues aimed at promotion of innovative activities and strengthening competitive performance of the regional cluster.

Application of the approach is supposed to help achieving a wide range of analytical tasks aimed, first of all, at determination of an optimum correlation between production output, arising production costs, and generated profit; second, at justification of the most appropriate range and volume of the products; third, at setting a threshold of financial sustainability and financial strength of the enterprise making part of the regional cluster in different functioning conditions.

\subsection{Objectives of the study}

Fulfillment of the purpose of the study necessitates achieving quite a few tasks and objectives including:

- review of evolution of the scientific approaches to determination and assessment of cluster-based organization and development of a particular economy along with identification of their unique features and peculiarities;

- generalization of the existing methodological approaches to evaluation of performance efficiency of the enterprises operating in the regional cluster;

- development of a baseline pattern and algorithms for assessment of the factors influencing the performance efficiency of the enterprise making part of the regional cluster;

- validation of the developed methodological approach using as an example performance of the enterprises functioning in one of the largest regional petrochemical clusters in Russia;

- working out practical recommendations for molding a development strategy of the enterprises making part of the industrial cluster.

\section{Literature Review}

Models of cluster-based development of economy and production pattern arrangement were suggested by a number of American scientists, namely M. Porter, M. Lorenzen, P. Maskell, S. Rosenfeld, M. Storper, M. Enright etc. One of the founders M. Porter devised a model of competitive advantages origination, according to which separate regions gain additional competitive advantages when the enterprises functioning in a particular industry sector are massed in one geographic location (Porter, 2005). According to the theory of territorial clusters suggested by M. Enright, competitive advantages are formed in the cluster at a regional level (Enright, 1992), with the regional clusters representing particular objects at which the clusterization policy is aimed.

S. Rosenfeld investigated the links between the enterprises functioning within the clusters and the associated organizations regarded as an essential element of the clusters, which significantly furthered the theory of regional clusters (Rosenfeld, 1997). In his opinion, regional clusters are not limited just by geographically concentrated location of interdependent firms. Moreover, the regional clusters should have the same liaison channels to facilitate production related transactions, as well as interaction and communication. This idea was further explicated in the writings by $\mathrm{P}$. Maskell and M. Lorenzen who came to the conclusion that network interaction between the firms arranged on the basis of the trust your partner principle is the main prerequisite for formation of a competitive regional cluster as well as for improvement of the competitive ability of the companies involved in the cluster (Maskell and Larenzen, 2003). French scientists J. Tolenado (Tolenado, 1978) and D. Soulie (Soulie, 1989) studied the cluster in the context of technological dependence of one sector of economy on the other, which is based on the need for creation of technological chains between the industry sectors for the purpose of realization of their potential advantages. A Swedish researcher $\mathrm{E}$. Dahmen defined a cluster as a constellation of sectors or "blocks of development" of an economy where a basis for progress is liaison between the sectors serving to ensure interdependent development (Dahmen, 1950). A modern model of cluster-based development has been devised by V. Feldman who defined a cluster as a diversified combination of 
industries and organizations bound up with relations that are based on the «cost - output» matrix (Feldman, 1999).

Various aspects relating to improvement of efficiency of the national economy and working out effective policy to be pursued at the regional management level were reviewed in a number of the studies by E. Bergman, E. Feser, D. Husby, M. Enright, A. Granberg etc. A significant contribution to development of the theory and practice of the economic analysis of enterprises was made by A. Bernstein, M. Brett, J. Richard, R. Thomas, G. Harman, E. Helfert, J. Schumpeter, P. Anthony Samuelson, R. Ackles and others.

However, notwithstanding a great number of the studies on the issues under review in this paper, no methodological approaches to carrying out management and control over upgrading of the regional clusters' performance efficiency have evolved until now.

\section{Research Methodology}

A mathematical apparatus was used to carry out an operational analysis aimed at identification of various factors influencing the performance efficiency of an enterprise making part of the petrochemical cluster. The choice is reasoned by the offered possibility to model variability of the efficiency indicators in different combinations of the factors under study. This point is of paramount importance from the point of view of mapping out a development strategy for an enterprise making part of the petrochemical cluster, planning its current and future business activities, assessment of potential effect of the decision-making process at the managerial level etc.

To that end, the amount of profit was taken as an indicator showing the performance efficiency of the enterprise. The interrelation of the key factors having the strongest impact on profit generation $(P)$ at the enterprise involved in the petrochemical cluster can be presented as follows:
$P=V \times(P P-P C-E C)$,

$V$ - volume of sales in kind; $P P$ - average unit price of product; $P C$ - prime cost (excl. energy cost) of a unit of product; $E C$ - energy cost per a unit of product.

It is worth noting that separation of energy cost as a factor calling for an independent analysis is caused by the fact that high energy intensity of the production complexes operated by the Russian enterprises making part of the petrochemical clusters is the major constraint on improvement of their competitive ability in the world market (Melnik and Lukishina, 2014; Melnik and Mustafina, 2014; Sadriev, 2014; Melnik and Dyrdonova, 2015). It should be pointed out that PJSC Nizhnekamskneftekhim (NKNK) is the biggest energy consumer compared to other enterprises operating in the petrochemical sector of the Republic of Tatarstan, with NKNK consumption rates reaching $10 \%$ of electric power and 30 $\%$ of thermal energy generated by the overall power grid of the region. Therefore in the current context the issues related to improvement of the energy efficiency of this enterprise appear to be particularly topical. The situation is aggravated by the constant escalation of prices for electricity and heat power supplied by the energy providers in the region.

According to the methodological approach proposed by the authors of this paper, the operational analysis of profit generated by the enterprise involved in the petrochemical cluster is suggested to be carried out in a phased manner.

Stage 1 of the operational analysis consists in determination of a degree of operating leverage with respect to each factor. An effect of operating leverage is manifested in the fact that any variation of the factor under study always results in a strong change in the profit. The following models are proposed to determine the degree of operating leverage:

$$
\begin{aligned}
& \text { DOLv }=\frac{M R}{P} \text {, } \\
& D O L_{P P}=\frac{S P}{P} \text {, } \\
& D O L_{P C}=\frac{P C}{P} \text {, } \\
& \text { DOLEC }=\frac{E C}{P} \text {, }
\end{aligned}
$$

$D O L$ - degree of operating leverage with respect to the factor under study: for volume of sales - DOLv; price $D O L_{P P}$; prime cost (excluding energy cost) - DOLPC; energy cost - DOLEC; $M R$ - marginal revenue; $P$ - profit; $S P$ - sales proceeds; $P C$ - prime cost excluding energy cost; $E C$ - energy cost.

Stage 2 of the operational analysis consists in a sensitivity analysis of gross profit generated by the enterprise vs. variation of one of the factors, for which the following model is used:

$P_{\%}=D O L \times F_{\%}$,

$P_{\%}$ - percent change in profit; $F$ \% - percent change in the factor under study. 
Stage 3 of the operational analysis consists in a break-even analysis differing from the conventional analysis by the fact that an objective of the break-even analysis is to determine a break-even point along with financial safety margin restricted to the volume of sales of the products manufactured by the enterprise. The financial safety margin here is taken to mean the volume of revenue which is currently in excess over the critical value at this enterprise.

The operational analysis procedure underpinned by the classical analysis of break-even operation of the enterprise, which is typically carried out to weigh the volume of sales, allows accommodating this analysis technique to assess influence of other factors, inclusive of costs and prices. For this purpose a break-even point and financial safety margin are determined with respect to each element of the operating leverage using the following models:

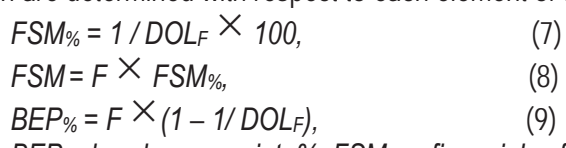

BEP - break-even point, \%; FSM\% - financial safety margin, \%; FSM - financial safety margin, abs. un.

Thus, the operational analysis of an enterprise represents an analysis of performance of an enterprise carried out on the basis of an analysis of profit to cost ratio, which allows identification of interconnections between the profit and cost indicators at different volumes of output. We believe that analysis of this type appears to be the most effective tool for planning and forecasting performance efficiency of an enterprise involved in an industrial cluster.

\section{Findings and Discussions}

Validation of the proposed methodological approach was conducted through the example of PJSC Nizhnekamskneftekhim. The calculation results are shown in Table 1 below.

Table 1 - Degree of operating leverage with respect to the factors under study

\begin{tabular}{|l|c|c|c|c|c|}
\hline Indicators & $\mathbf{2 0 1 0}$ & $\mathbf{2 0 1 1}$ & $\mathbf{2 0 1 2}$ & $\mathbf{2 0 1 3}$ & $\mathbf{2 0 1 4}$ \\
Degree of operating leverage by the volume of sales (DOLv) & 3,95 & 4,28 & 4,56 & 5,81 & 4,22 \\
Degree of operating leverage by price (DOLPP) & 4,66 & 5,04 & 5,40 & 7,22 & 5,07 \\
Degree of operating leverage by prime cost (excluding energy cost) (DOL $\left.L_{P C}\right)$ & $-2,95$ & $-3,28$ & $-3,56$ & $-4,81$ & $-3,22$ \\
Degree of operating leverage by energy cost $\left(D O L_{E C}\right)$ & $-0,71$ & $-0,77$ & $-0,84$ & $-1,42$ & $-0,85$ \\
\hline
\end{tabular}

The results obtained in the course of the case study allow for the conclusion that the strongest effect on the amount of profit generated by PJSC Nizhnekamskneftekhim is produced by the price factor. The degree of operating leverage varies within $4.66-7.22$. Volume of sales, by its impact on the amount of profit, ranks next to price. The degree of operating leverage with respect to the volume of sales factor varies within $3.95-5.81$. The degree of impact of the remaining factors is somewhat lower. As far as prime cost is concerned, this factor varies within $2.95-4.81$ without including energy cost, while the energy cost factor varies within $0.71-1.42$.

Further, after having processed relevant information covering the performance indicators demonstrated by PJSC Nizhnekamskneftekhim, a scale of assessed factors variation was developed along with assessment of an impact exerted by each of the factors on the amount of profit (Table 2).

Table 2 - Profit sensitivity to variation of the factors under study

\begin{tabular}{|c|c|c|c|c|c|c|c|c|c|c|c|c|c|}
\hline & DOL & \multicolumn{12}{|c|}{ Percent change of profit in case of variation of a relevant factor by } \\
\hline $\mathrm{Fa}$ & 2014 & $-15 \%$ & $-10 \%$ & $-9 \%$ & $-6 \%$ & $-5 \%$ & $-3 \%$ & $+3 \%$ & $+5 \%$ & $+6 \%$ & $+9 \%$ & $+10 \%$ & $+15 \%$ \\
\hline Volume of sales & 4,22 & $-63,3$ & $-42,2$ & $-37,98$ & $-25,32$ & $-21,1$ & $-12,66$ & 12,66 & 21,1 & 25,32 & 37,98 & 42,2 & 63,3 \\
\hline Price & 5,07 & $-76,05$ & $-50,7$ & $-45,63$ & $-30,42$ & $-25,35$ & $-15,21$ & 15,21 & 25,35 & 30,42 & 45,63 & 50,7 & 76,05 \\
\hline Prime cost (excl. energy cost) & $-3,22$ & 48,3 & 32,2 & 28,98 & 19,32 & 16,1 & 9,66 & $-9,66$ & $-16,1$ & $-19,32$ & $-28,98$ & $-32,2$ & $-48,3$ \\
\hline Energy cost & $-0,85$ & 12,75 & 8,5 & 7,65 & 5,1 & 4,25 & 2,55 & $-2,55$ & $-4,25$ & $-5,1$ & $-7,65$ & $-8,5$ & $-12,75$ \\
\hline
\end{tabular}

The results obtained in the course of the case study allow for sizing up the percent change in the amount of profit in case of variation of one of the factors by some percentage. For example, when the volume of sales increases by $15 \%$ the gross profit will increase by $63.3 \%$, whereas if the energy cost increases by $10 \%$ the gross profit will decrease by $8.5 \%$.

To demonstrate the obtained results, a profit elasticity graph vs. the factor under study was plotted on the basis of the data from Table 2 (Figure 1). 


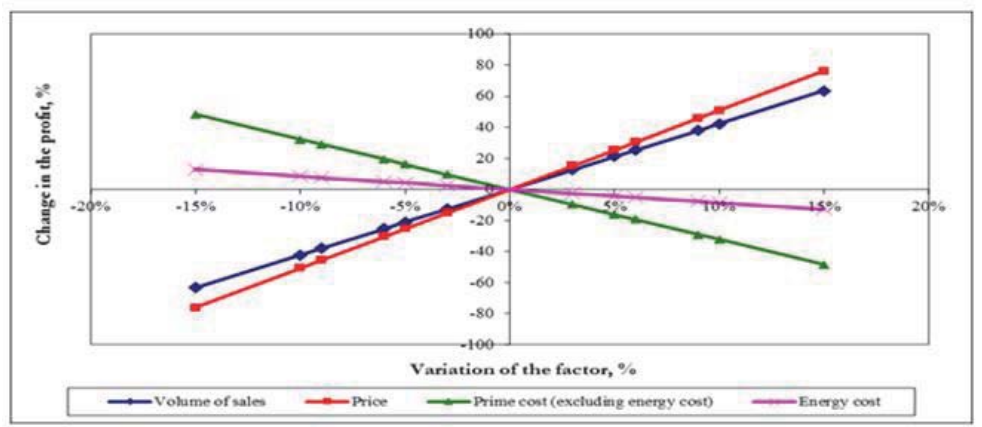

Figure 1 - Profit elasticity vs. the factors under study

The results obtained in the course of the case study suggest that the higher the inclination of a straight line (Fig. 1) the higher the elasticity of profit with respect to variation of the factors under study. Inclination of a straight line is determined based on the degree of operating leverage, where the higher the degree of operating leverage with respect to the factor under study, the higher inclination of the straight line.

The graph shown in Figure 1 allows considerable expansion of analytical capabilities with respect to the managerial decision-making process, whilst making it possible, first, to predict changes in profits in case of variation of different factors; second, to identify the factors which, when modified, could facilitate achievement of operating and strategic objectives of development of the enterprise; third, make a justified evaluation of the scope of necessary changes to gain the desired results.

The break-even analysis results covering the enterprise under study are presented in Table 3 below. The results obtained in the course of the case study allow for the conclusion that of critical importance are the following values of the factors under study when observed from the point of view of a potential loss of profit in case of variation of any of the factors: decrease in the volume of sales by $23.7 \%$; price reduction by $19.72 \%$; increase in prime cost (excluding energy cost) by $31.06 \%$, and increase in energy cost by $117.65 \%$.

Table 3 - Evaluation summary of break-even analysis results

\begin{tabular}{|l|c|c|c|c|c|}
\hline Factors & DOL (2014) & Value (2014), thous RUB & BEP, thous RUB & FSM, thous RUB & FSM, \% \\
Volume of sales & 4,22 & 94407096 & 72035746 & 22371350 & 23,70 \\
Price & 5,07 & 34,25 & 27,49 & 6,76 & 19,72 \\
Prime cost (excluding energy cost) & $-3,22$ & 60001824 & 78635931 & -18634107 & $-31,06$ \\
Energy cost & $-0,85$ & 15768518 & 34319716 & -18551198 & $-117,65$ \\
\hline
\end{tabular}

Table 3 allows for plotting a graph showing the financial safety margin of the enterprise based on the factors under study (Figure 2).

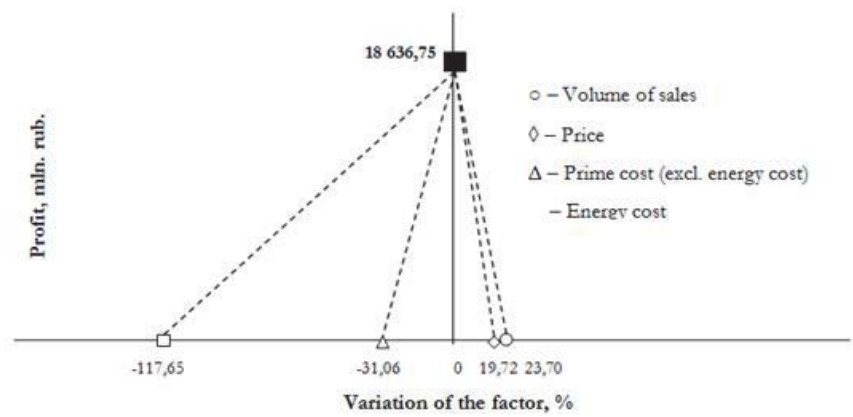

Figure 2 - Financial safety margin of the enterprise based on the factors under study 
The financial safety margin graph plotted on the basis of the factors under study allows for determination of an amount of profit generated by the enterprise in case of variation of any of the factors under study, as well as assessment of variation of a numerical value of any of the factors under study at the specified rate of change in the profit.

\section{Conclusions}

The proposed methodological approach allows creating the necessary background for modelling an effect produced by different factors on performance efficiency of the enterprises involved in the regional industrial cluster. When used as intended, the technique makes it possible to select the most preferred combination of the factors from the point of view of achievement of target performance indicators of the particular enterprise. An essential advantage of the presented approach is that practical application of this technique when utilized for solving applied problems relating to the functioning of enterprises does not call for large amounts of background information which could be easily obtained from standard account ledgers.

\section{Acknowledgements}

This work was funded by the subsidy allocated to Kazan Federal University for the state assignment in the sphere of scientific activities.

\section{References}

Dahmen, E. (1950). Business and development of Swedish industry, 1919-1939. Stockholm, 360.

Enright, M.J. (1992). Why Clusters are the Way to Win the Game? Word Link. 5 (July/August), 24-25.

Feldman, V.P. (1999). Innovation in cities: Science, based on diversity, specialization and localization competition. European Economic Review. 43, 409-429.

Maskell, P. \& Larenzen, M. (2003). The Cluster as Market Organization. DRUID Working Paper. 14, 29.

Melnik, A.N.\& Dyrdonova, A.N. (2014). Formation and development of industrial clusters in the region. SGEM 2014 International Multidisciplinary Scientific Conferences on Social Sciences and Arts. Vol. 3, 215-222.

Melnik, A.N. \& Dyrdonova, A.N. (2014). Infrastructural support for development of the territorial petrochemical cluster. Mediterranean Journal of Social Sciences. Vol. 5 (18), 299-304. Doi: 10.5901/mjss.2014.v5n18p299.

Melnik, A.N. \& Dyrdonova, A.N. (2015). Energy efficiency improvement ways in industrial clusters of the region. Mediterranean Journal of Social Sciences. Vol. 6 (3), 141-145. Doi: 10.5901/mjss.2015.v6n3s5p141.

Melnik, A.N. \& Lukishina, L.V. (2014). The use of index approach for enterprise energy strategy formation. Mediterranean Journal of Social Sciences, 5(18), 289-292. DOI: 10.5901/mjss.2014.v5n18p289.

Melnik, A.N. \& Mustafina, O.N. (2014). The Liberalization of Electricity Market in the System of Measures for Improving Industrial Enterprisers Competitiveness: The Case of Russia. Mediterranean Journal of Social Sciences, 5(18), 293-298. DOI: 10.5901/mjss.2014.v5n18p293.

Melnik, A.N. \& Mustafina, O.N. (2014). The liberalization of electricity market in Russia. Asian Social Science, 10 (13), 280-286. DOI: 10.5539/ass.v10n13p280.

Porter, M. (2005). Competition: Per. from English. M.: Publishing House «Williams», 258.

Rosenfeld, S.A. (1997). Bringing Business Clusters into the Mainstream of Economic Development. European Planning Studies. 5, 3-23.

Sadriev, A.R. (2014). World patent practice analysis in the area of energy-efficient and energy-saving technologies. Mediterranean Journal of Social Sciences, 5 (18), 283-288. http://dx.doi.org/10.5901/mjss.2014.v5n18p283.

Sadriev, A.R. \& Pratchenko, O.V. (2014). Idea management in the system of innovative management. Mediterranean Journal of Social Sciences, 5 (12), 155-158. DOI: 10.5901/mjss.2014.v5n12p155.

Soulie, D. (1989). Filieres de Production et Integration Vertical. Janvier: Annales des Mines, 21-28.

Tolenado, J.A. (1978). Propjs des Filires Industrielles. Revue d'Economie Industrielle. Vol. 6. (4), 149-158. 